\title{
Nonstop Flying Is Safer Than Driving
}

\author{
Michael Sivak, ${ }^{1}$ Daniel J. Weintraub, ${ }^{1}$ and Michael Flannagan ${ }^{1}$
}

Received April 27, 1990; revised August 15, 1990

\begin{abstract}
The relative safety of driving and flying is important in many situations that involve selecting a mode of transportation. The traditional view, that flying via scheduled airlines is safer than driving, has recently been challenged by Evans et al. ${ }^{(1)}$ They concluded that for a low-risk driver it is safer to drive on rural interstate highways (the safest roads) than to fly if the trip length is less than 602 miles. We reestimated the fatality probabilities for flying by taking into account that the risk of flying is dependent on the number of nonstop segments flown, but, for all practical purposes, is independent of the length of the trip. Our calculations indicate that, for average or high-risk drivers, it is always safer to fly than to drive. Furthermore, even for a low-risk driver, nonstop flying is safer than driving on rural interstate highways for a trip distance of more than 303 miles; the corresponding breakeven distances for flights that involve two and three segments are 606 and 909 miles, respectively.
\end{abstract}

KEY WORDS: Flying; driving; risk; decision-making.

\section{INTRODUCTION}

In many situations, a person has the option of selecting a mode of transportation. In such situations, the relative risks involved (in addition to cost, time, and convenience) are worth considering in making the choice. A frequent measure of risk in transportation is the number of fatalities per billion person miles (or other similar travel units). Using such a measure, automobile travel appears to be several times more risky than travel via scheduled airlines.

Recently, Evans et al. ${ }^{(1)}$ have posed a set of conceptual problems with such a comparison. First, air-fatality rates are for passengers only, whereas road-fatality rates are usually for all persons involved (including drivers, passengers, pedestrians, etc.). Second, the relevant comparison for air travel should be road travel on rural interstate highways (which turn out to be the safest roads). Third, the road-fatality rates vary substantially by driver and vehicle characteristics, such as age, sex, alcohol and

\footnotetext{
+ The University of Michigan Transportation Research Institute, Ann Arbor, Michigan 48109-2150.
}

belt use of the driver, and weight of the automobile. Fourth, since most air crashes occur at or near the beginning or end of the trip, the fatality risk per flight is, for all practical purposes, independent of the scheduled length of the trip. (Consequently, the number of air fatalities per mile traveled decreases with an increase in the length of the trip.) To illustrate these points, Evans et al. presented both traditionally computed fatality rates and alternative rates taking the above arguments into account. According to Evans et al., the average (traditionally computed) fatality rate for the U.S. scheduled airlines during $1978-1987$ was 0.55 fatalities per billion passenger miles, while the road-fatality rate for 1987 was 24.1 fatalities per billion vehicle miles. However, Evans et al. calculated that "the risk for a 40 -year-old, alcohol-free, belted driver traveling on rural interstate roads in a car 700 pounds heavier than average is . . 0.804 driver fatalities per billion miles driven" (p. 243). In contrast, the air-fatality rates are less than 0.804 per billion miles only for a trip length of more than 602 miles (e.g., 0.605 for 800 miles), but are more than 0.804 for a trip length of less than 602 miles (e.g., 1.936 for 250 miles). Consequently, Evans et al. con- 
cluded that "the low-risk driver has a lower fatality risk on trips of less than 600 miles if he drives rather than flies"' (p. 244).

The points made by Evans et al. are incisive. However, the aim of the present article is to argue that: (1) the air-fatality rate for nonstop flights is substantially less than the rate derived by Evans et al.; and (2) since air-fatality rate per flight is assumed by Evans $e t$ al. to be independent of the length of the trip, air-travel calculations that avoid passenger miles of travel are more appropriate. The implication of these arguments is that driving appears to be safer than flying only for substantially shorter distances than suggested by the analysis of Evans et al.

\section{AIR-FATALITY RATES BASED ON PASSENGER MILES}

Evans et al. ${ }^{(1)}$ calculated the average $1978-1987$ air-fatality rate of all scheduled U.S. airlines to be 484 fatalities per billion passenger flights. This was based on the fatality rate per billion passenger miles of 0.55 , and on the assumptions that: (1) the rate per flight is independent of the length of the trip; and (2) the average length of a trip during the 1980 s was 880 miles. However, the average nonstop flight segment during 19781987 was 551 miles. ${ }^{(2)}$ Consequently, the 880-mile benchmark flight of Evans et al. consisted, on the average, of 1.6 ( 880 divided by 551) nonstop segments. Therefore, the recomputed average fatality rate per billion passenger nonstop flights (using the approach and data sources of Evans et al.) is 302 fatalities (equivalent to dividing the above 484 by 1.6).

Evans $e t$ al. calculated the air-fatality rate per billion passenger miles for $1978-1987$ to be 0.55 by averaging the 10 annual rates provided by NSC. ${ }^{(3)}$ This is not fully justified, since the annual passenger miles during this period have been rising substantially. ${ }^{(4)}$ Furthermore, the rates provided by NSC are rather imprecise, with eight of the 10 annual rates having only one significant digit. We recomputed the air-fatality rate by dividing the total number of fatalities during this period$1,332^{(5)}$ - by the total number of passenger miles$2,946,893,891,000$. $^{(4)}$ The resulting rate is 0.452 fatalities per billion passenger miles. By multiplying this rate with the length of the average nonstop segment (551 miles), we obtained the average fatality rate per billion passenger flight segments to be 249 fatalities (about 1.94 times less than the rate derived by Evans $e t a l$.).

\section{AIR-FATALITY RATES BASED ON FLIGHT SEGMENTS}

The assumption by Evans et al., that flying is independent of the length of the flight, is compelling and supported by evidence (e.g., see Ref.' 6). Let us, then, reformulate the air-fatality risk without resorting to passenger miles traveled, building on the basic flying unit, the flight segment, rather than the trip (point of origin to point of destination). Flight segments are, by definition, nonstop and therefore discrete. (The 1.6 segments per average flight, referred to above, was used as a statistical correction.) Therefore, the comparison between the safety of air travel and automobile travel is complicated by the problem that segments are the logical unit of measure for one, and distance for the other. Our analysis will take this into account.

What is needed for aircraft passengers is the probability that a particular passenger will be killed on a nonstop (one segment) flight, $p\left(f_{1}\right)$, which can be estimated by taking a proportion, the number of passenger fatalities divided by the total number of segments flown by all passengers in the same time period. For the period of 1978-1987, there were 1332 passenger fatalities, ${ }^{(5)}$ $55,267,218$ nonstop segments, ${ }^{(4)}$ and the average number of passengers per nonstop segment was 98.8. ${ }^{(2)}$ Therefore,

$$
\begin{aligned}
p\left(f_{1}\right) & =\frac{1332 \text { fatalities }}{55,267,218 \text { segments } \times 98.8 \text { on board }} \\
& =244 \times 10^{-9}
\end{aligned}
$$

or 244 fatalities per billion passenger flight segments. This probability $\left(244 \times 10^{-9}\right)$ is in excellent agreement with the probability derived earlier using passenger miles traveled $\left(249 \times 10^{-9}\right)$.

\section{ROAD-FATALITY RATES}

As indicated above, according to the calculations of Evans et al.,(1) the fatality risk for a 40 -year-old, alcohol-free, belted driver traveling on rural interstate roads in a car 700 pounds heavier than average is 0.804 driver fatalities per billion miles driven. Evans et al. present calculations indicating that such a low-risk driver is about 613.6 times less likely to be involved in a fatal accident than a high-risk driver, exemplified by Evans et al. as an 18-year-old male, intoxicated, unbelted, traveling in a car that is 700 pounds lighter than average (but on the same roads-rural interstates). Thus, for such a driver the fatality risk is 493.3 driver fatalities per 
billion miles driven. The analogous risk for the average driver (based on aggregate fatalities and aggregate miles driven, but corrected for driving on rural interstates) is 6.66 driver fatalities per billion miles driven (based on the information in Evans et al. $\left.{ }^{(1)}\right)$.

\section{PERSONAL DECISION-MAKING}

Evans et al. considered the data from the standpoint of an individual traveler's decision: Under the given conditions should I drive (myself) or fly as a passenger? Driving risk involves the distance driven (with number of stops considered irrelevant), while flying risk considers only the number of (nonstop) flight segments (a variable not dealt with by Evans et al.). The representation in Fig. 1 depicts the traveler's prospects for air and road trips of varying length and nonstop segments. Probability of becoming a fatality, $p(f)$, is the ordinate, trip distance the abscissa. Flights with varying number of nonstop segments plot as a set of horizontal lines. Driving risk increases with miles driven; flying risk with segments flown.

Figure 1 is a diagram suitable for personal decisionmaking. It relies directly upon the Evans et al ${ }^{(1)}$ analysis of the automobile-driving data, and on our reanalysis of the air-travel situation that considers passenger fatalities in relation to nonstop segments flown (rather than miles traveled). One enters with the number of flight segments to be flown, and the requisite driver risk function. Where the two cross is the indifference point for the driving distance. If the actual driving distance is less than the indifference distance, it is safer to drive than to fly.

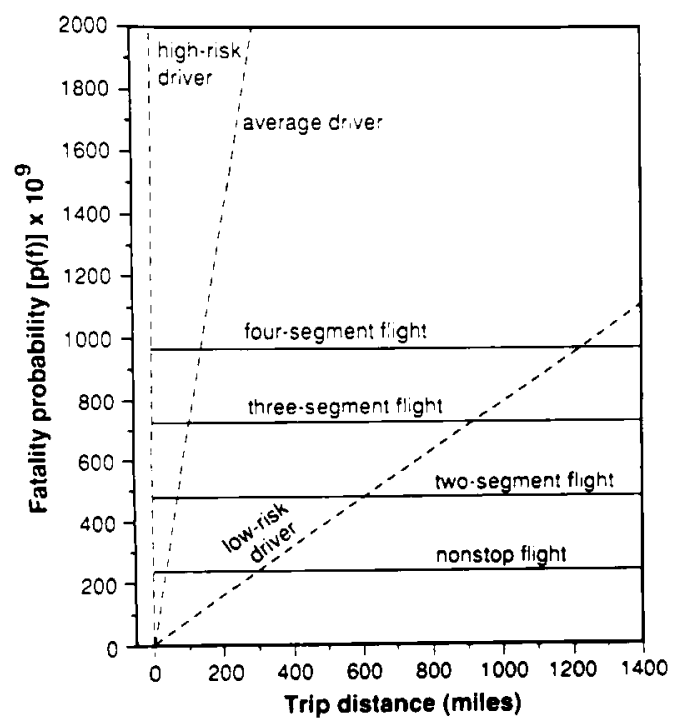

Fig. 1. Fatality probabilities for actual driving and flying.
Let us consider three examples. In the first example, the flight under consideration is a nonstop (onesegment) flight. The indifference distances for a nonstop flight and for low-risk, average, and high-risk drivers (as discussed above) are 303 miles, 37 miles, and 0.5 miles, respectively (see Fig. 1). Consequently, for a lowrisk driver it is safer to fly nonstop than to drive if the road distance is more than $\mathbf{3 0 3}$ miles; the corresponding indifference distances for average and high-risk drivers are 37 miles and 0.5 miles, respectively.

In the second example, only a three-segment flight is available. For such a situation, it is safer to fly than to drive if the distance is more than 909 miles for a lowrisk driver, 111 miles for an average driver, and 1.5 miles for a high risk driver.

In the third example, a low-risk driver is considering a 602-mile trip (602 miles being the indifference distance obtained by Evans $e t$ al. for a low-risk driver). However, the present calculations indicate that for such a situation the risk of driving is about twice the risk of flying on a nonstop flight.

\section{STATISTICAL CONSIDERATIONS}

Figure 1 displays straight lines for fatality probabilities in driving and equally spaced horizontal lines for fatality probabilities in flying. Probability of a fatality does not actually increase linearly with driving distance or number of flight segments, and the appearance of Fig. 1 may suggest that it is based on a linear approximation to a nonlinear function. In fact, over the ranges used in Fig. 1 the actual functions are simply not distinguishable from linear approximations. When $p(f)$ is near zero, as it is here, assuming that the ratio of $p(f)$ to the number of miles driven or the number of segments flown is a constant (a linear relationship), will produce risk probabilities inconsequentially different from more appropriate risk formulations. For example, to compute the probability for a two-segment flight more appropriately, one must combine the probabilities of being a fatality on either segment. If $p\left(f_{1}\right)$ is the probability of a fatality for a one-segment (nonstop) flight, then the probability of a fatality for a two-segment flight $p\left(f_{2}\right)=p\left(f_{1}\right)+$ $p\left(f_{1}\right)\left[1-p\left(f_{1}\right)\right]$, because one must survive segment one with a probability of $1-p\left(f_{1}\right)$ to become a fatality on segment two. Thus, $p\left(f_{2}\right)=2 p\left(f_{1}\right)-\left[p\left(f_{1}\right)\right]^{2}$ which is nearly $2 p\left(f_{1}\right)$, since the square of $244 \times 10^{-9}$ is such a small number relative to $2 p\left(f_{1}\right)$. However, if $p\left(f_{1}\right)$-and, consequently, $p(f)$-were large, the linear approximation would fail badly. [See Fig. 2 for the situation when $p\left(f_{1}\right)$ $=0.4$.] 
It is assumed that $p(f)$ per flight segment and $p(f)$ per mile driven are constant (constant hazard functions), and that $p(f)$ for drivers is related to trip length by a negative-exponential function, $p(f)=1-e^{-k d}, d$ being trip distance and $k$ a constant estimated by the ratio of total driver fatalities to total driver miles. (It is also assumed that $k$ is the same for all driver-automobile combinations.) An important property of this function is that, for all practical purposes, it is linear at the near-zero $p(f)$ values considered here. That is, however, not the case for high fatality rates, as shown in Fig. 2 for a situation where $k=0.002$.

The linear approximation also fails when either the driving distance or the number of flight segments is prohibitively large. Eventually, for very large driving distances (in billions of miles) or flight segments (in millions of segments), the linear approximation would lead to a $p(f)$ exceeding 1.0 .

\section{CONCLUSIONS}

Evans et al. ${ }^{(1)}$ have argued that for a low-risk driver it is safer to drive than to fly if the trip distance is less than 602 miles. However, when driving is compared to nonstop flying, a different picture emerges. The present calculations indicate that for a low-risk driver (exceptionally low-risk as defined by Evans et al.) it is more risky to drive (on rural interstates - the safest roads) than

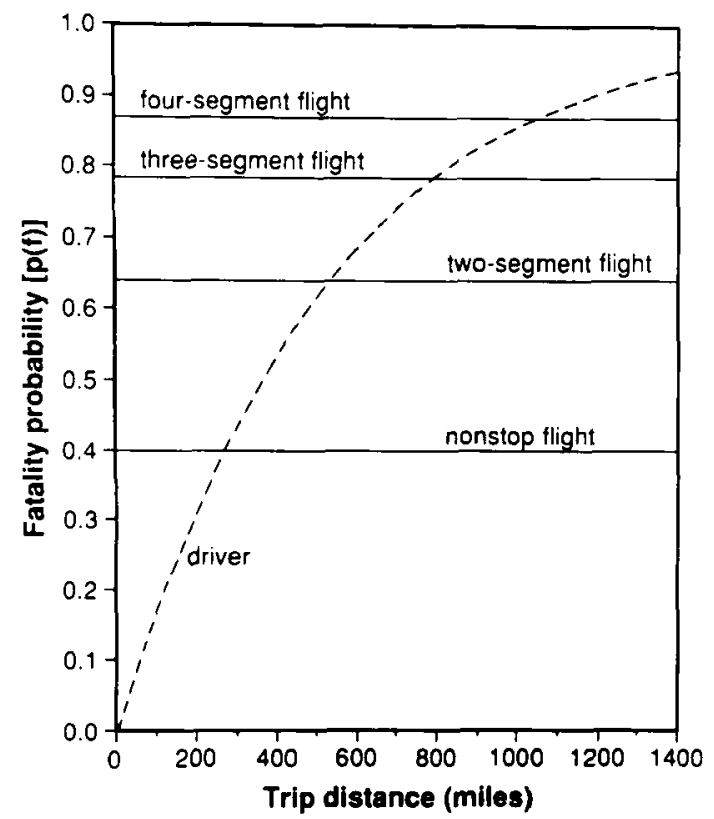

Fig. 2. Fatality probabilities for hypothetical ultra-high-risk driving $(k=0.002)$ and flying $\left[f\left(p_{1}\right)=0.4\right]$. to fly via scheduled airlines if the driving distance is more than 303 miles. If the distance is 551 miles (the average length of a nonstop air segment), then the driving-fatality risk for a low-risk driver is 1.82 times greater than the air-fatality risk. The corresponding risk-factors for average and high-risk drivers are 15 times greater and 1114 times greater, respectively.

Each nonstop segment of a flight increases the risk by approximately the same amount. Consequently, a flight with three segments (two intermediate stops) is approximately three times as risky as a nonstop flight. For average or high-risk drivers the indifference distances are so small that for any reasonable combinations of the trip distance and number of flight segments (e.g., 150 miles or more, and four or fewer flight segments), flying is always safer than driving. [The above analysis, as well as the analysis by Evans $e t$ al., considered only fatalities. Since "injuries exceed fatalities by about a factor of 70 in road traffic, but are less numerous than fatalities in airline crashes (Evans et al. ${ }^{(1)}$, p. 13)" an analysis that includes both fatalities and injuries would make driving appear even more risky.]

In the derivation of the air-fatality rate, we (as well as Evans et al.) considered all scheduled domestic airlines (including commuter). It is easy to visualize better approximations to true $p(f)$ by making the flight $p(f)$ specific to a particular airline and aircraft, and by including the drive to and from the airports in the $p(f)$ for a "flying trip." Similarly, better approximations to $p(f)$ for a "driving trip" are possible by subdividing miles driven into miles on different types of roadways, during different times of day, etc., and by specifying additional risk functions lying to the lower-risk side of the "average driver" in Fig. 1, where most of us confidently believe we belong. ${ }^{(7,8)}$

\section{REFERENCES}

1. L. Evans, M. C. Frick, and R. C. Schwing, "Is it Safer to Fly or Drive? A Problem in Risk Communication," Risk Analysis 10, 239-246 (1990).

2. Civil Aeronautics Board and Department of Transportation, Air Carrier Traffic Statistics (U.S. Government Printing Office, Washington, D.C., 1979-1988, published monthly).

3. National Safety Council, Accident Facts, 1988 ed. (Chicago, 1988).

4. Air Transport Association of America, Air Transport 1988. The Annual Report of the U.S. Scheduled Airline Industry (Washington, D.C., 1989).

5. National Safety Council, Accident Facts, 1989 ed. (Chicago, 1989).

6. D. C. Nagel, "Human Factors in Aviation Operations," in E. L. Wiener and D. C. Nagel (eds.), Human Factors in Aviation (San Diego, Academic Press, 1988), pp. 263-303.

7. O. Svenson, "Are We All Less Risky and More Skillful Than Our Fellow Drivers?" Acta Psychologica 47, 143-148 (1981).

8. M. Sivak, J. Soler, and U. Tränkle, "Cross-Cultural Differences in Driver Self-Assessment," Accident Analysis \& Prevention 21, 371-375 (1989). 